\title{
Nursing students' cultural immersion in Kenya: A case for a clinical capstone site
}

\author{
Nancy C. Wilk \\ Wegmans School of Nursing, St. John Fisher College, Rochester, USA \\ Correspondence: Nancy C. Wilk. Address: Wegmans School of Nursing, St. John Fisher College, 3690 East Avenue, \\ Rochester, NY 14618, USA. Email: nwilk@sjfc.edu. \\ Received: June 15, 2012 \\ Accepted: August 24, $2012 \quad$ Online Published: December 10, 2012 \\ DOI : $10.5430 /$ jnep.v3n5p39 \\ URL: http://dx.doi.org/10.5430/jnep.v3n5p39
}

\section{Abstract}

Awareness of cultural concepts is an important component of nursing education and cultural immersion experiences are invaluable in fostering understanding of them. These types of experiences take students out of their comfort zone and challenge them both personally and professionally.

For several years, students on all levels have been participating in a 10-day trip to Kenya led by nursing faculty. Undergraduate students who go on the trip receive clinical credit for their community health course and are required to journal daily about their experiences while on the trip and write a reflection paper for the course when they return. The content of these papers was analyzed for common themes to determine what students learned from the trip and to see if it was worthwhile to allow students to do their clinical capstone experience in Kenya, that would be part of the schools new curriculum.

Four main themes emerged from the student reflection papers. They were: "Making a difference", "Not knowing what to expect”, "Feeling like a real nurse" and "Renewing my Identity". The Kenya experience has fostered student growth in various ways and our school of nursing will continue to support this learning experience by encouraging senior students to complete their clinical capstones in Kenya.

\section{Key words}

Cultural competence, Nursing students, Immersion experiences

\section{Activity description}

Instilling students with an awareness of cultural concepts has been an important component of nursing education for many years; and according to the American Association of Colleges of Nursing (AACN), an end-of-program goal for nursing programs should be the ability to utilize knowledge of social and cultural factors that impact nursing care ${ }^{[1]}$. Various educational methods have been used to assist students in their understanding of a diversity of cultures and the role culture plays in both illness and health. Role-playing, case studies, videos, readings, and discussion have all been utilized in the classroom setting, but surely one of the most important methodologies is experiential, whereby students actively engage with cultures other than their own ${ }^{[2]}$. Opportunities for these types of interactions can be found close to home: an educator can invite a guest speaker to lecture for a day; or students can incorporate community clinics, day-care centers, or soup kitchens into their clinical rotations. While each of these examples is certainly valuable, it is hard to compare them to the 
full cultural immersion offered by a service trip or study-abroad program. Trips like these are extremely important because they often require a good deal of emotional effort, and they remove the student from his or her comfort zone. Students are confronted with situations they are not familiar with and may see extreme poverty and suffering of other human beings. These factors broaden the students' worldview and provide perspective on their own lifestyle. At our nursing school, we are committed to providing opportunities for our students to experience nursing in a foreign country because we believe in the transformative power that these types of experiences have on students' cultural understanding. It is for this reason that over the past four years, members of our faculty have accompanied undergraduate and graduate nursing and pharmacy students to Kenya to learn about Kenyan culture and to provide nursing care for the people who live there. This paper will outline our experiences in developing, planning, and executing an annual 10-day trip to Kenya. It will also discuss common themes found in the student reflection papers about their experiences.

\section{Genesis of a cross-cultural trip}

The idea for a school of nursing mission trip was conceived in the fall of 2007 when one of our students, a young man who was born and raised in a small village in western Kenya, spoke to his class of the medical needs of the rural Kenyan people and how they would benefit from the expertise of our nursing faculty and the enthusiastic willingness of our students. My interest was immediately piqued because I had been on mission trips with nursing students in Guatemala and the Lakota Sioux reservation in South Dakota.

I very quickly became immersed in the many challenges of planning a trip for 16 college students and their faculty chaperones. How does one transport a dozen young students across the country of Kenya? How does one pay for housing, transportation, and food on a shoestring budget? With these, and many more questions racing through my mind, I made the fortuitous acquaintance of a local philanthropist who had traveled extensively in Kenya, building clinics and equipping hospitals. He provided me with contact information for people that could set up visits to hospitals and clinics as well as a list of people that could assist with general travel needs while we were in the country. Furthermore, a few months before our trip, he spent an evening showing the students slides and talking about his experiences in Kenya. Without this man's contributions, our trip to Kenya surely would have suffered in efficiency and comfort, and perhaps, ultimately, in our overall goals of educating ourselves and offering health care where and when it was possible.

The first group consisted of two faculty members, four undergraduate nursing students, one master's-prepared family nurse-practitioner student, three pharmacy students, two registered nurses, an undergraduate biology major, as well as a writer, a photographer, and an interior-design major (the friend of one of our students who, as it turned out, was remarkably earnest and involved). The purpose of the trip was to educate ourselves about the Kenyan health-care system, to compare our own nursing knowledge with that of medical and nursing professionals we would meet in Kenya, and to offer our nursing assistance to the citizens of the rural communities we would be visiting. To accomplish these goals, we planned to visit different types of hospitals and clinics; talk with nurses, physicians, and people in the villages; and hold two screening clinics in the village where our Kenyan student had lived.

\section{Planning the second trip}

The experiences of that first trip and the people we met left us feeling invigorated and inspired. Despite certain obvious hardships, the rural Kenyans we lived with over the short course of a week were thankful for what they had; and they lived each day with a joyfulness that was, and still is, humbling. On a logistical note, I realized that the students needed a better understanding of and better preparation for the conditions of this type of trip. Unfortunately, a number of the group were disturbed by the standard third-world conditions we found in Kenya: for example, the fact that there was a lack of hot, running water; that the toilets did not flush; that the food was different; and that the mosquitoes were malaria-ridden. However, despite these challenges, it was abundantly clear that the group found the experience to be both profound and 
rewarding; and so, upon our return, I immediately began to prepare, if at first only mentally, for a similar trip the following spring. The other important thing we learned was the value in collaborating with the school of pharmacy, as their students assisted with medication teaching and administration, providing an added dimension and perspective for the nursing students to relate to. It provided the two groups of professional students the opportunity to practice collaborating and begin to understand the cultural differences between the two professions.

Upon our return, we fortuitously met two gentlemen that had been building schools in Kenya for five years and had established a not-for-profit organization. We discussed the value in forming a partnership and working together to provide health care to the people of the village where they had been working and to assist them in planning a new health clinic that they would build next to the schools. With the new partnership in place, plans for the May 2010 trip began in the fall of 2009 with full support from the nursing-school and pharmacy-school deans, the nursing school's associate dean, and the college president. Several more faculty from both the nursing and pharmacy schools were interested in traveling to Kenya with nursing and pharmacy students; so planning meetings were held twice monthly to develop a formal course called "Global Health Nursing: Kenya," complete with a course description, goals, and learning objectives. The course consisted of seven meetings, each with a specific focus. The topics included an introduction to Kenyan history, culture, geography, and economics; health care, nursing and pharmacy education; health teaching topics for the students; a review of assessment skills (particularly of laboring and postpartum women and the newborn); taking care of one's self in a developing country; fundraising; and trip preparation. The most commonly seen medical nursing diagnoses were reviewed, including important assessment data needed and treatment. Mental-health issues that are prevalent such as depression, consequences of physical and sexual abuse, the stigma of living with HIV, and the consequences of alcohol abuse were also included.

Planning also included how to solicit student applications, develop interview questions, and do final participant selection during the fall semester. The 27 participants included ten undergraduate, two masters, and two doctoral nursing students; one pharmacy student and one pharmacy faculty; three nursing faculty; three RNs; and five other interested members of the college community. All participants attended the monthly meetings and were able to collaborate with team members from the various groups represented. These meetings provided a venue to "practice" professional collaboration within a safe environment. Guest speakers included the men we were working with who had built schools in Kenya, the Kenyan student who by then had graduated, a student who had been successful in raising funds for a previous trip, and a nurse from a global health clinic who discussed personal safety and care and gave required immunizations. Having the global-health-clinic nurse come to the school ensured that every student received the appropriate immunizations and reduced the cost for each participant. These twice-monthly meetings helped relieve anxiety by providing students with information about the country and people of Kenya; how to prepare for the trip emotionally, physically, and financially; what to bring and not to bring; and trip logistics. The most important benefit of the meetings was to promote group cohesiveness. No official fund-raising sponsored by the school of nursing took place; but students were encouraged to raise funds on their own, using the suggestions from the student who was successful in the past. Many students raised a substantial amount toward their trip expenses by speaking to their church groups, posting on social networking sites, asking for donations, and various other methods.

The May 2010 Kenya trip was an overwhelming success. Two health-screening clinics were conducted at Mbako Oromo Primary and High School for the 600 children who attend school there. All children were treated for worms, given a mosquito bed-net with instruction on malaria prevention, and received a toothbrush and toothpaste with instruction on how to use them. The students along with a faculty member discussed STI prevention as well. Screening for head fungus and jiggers was done and treatment given when needed. Other opportunities for student participation included tours of different types of hospitals, working at orphan-feeding programs and in an orphanage, and providing both inpatient and outpatient care at a small Anglican hospital. The students learned firsthand about rural Kenyan culture. Collaborating with the not-for-profit agency helped us to build in these experiences, while at the same time making the trip run smoothly. Our 
experience with having someone "on the ground" in a foreign country underscores the importance of this type of partnership.

\section{Outcomes}

Junior nursing students who traveled to Kenya in the 3 years prior to instituting our new curriculum (2009-2011) were credited with clinical hours for the community-health course that they took during the second semester of their junior year. For this course, they were required to write a paper describing what they learned from the trip and their experiences working with the people of Kenya, concentrating on the cultural differences they saw. Reflecting upon and writing about their experiences on a trip such as this can assist students in developing cultural competence ${ }^{[2]}$. Content analysis was used to identify common themes that described what the trip meant to them, what they had learned, and how they had changed as people.

\section{Themes}

The papers were read by the faculty who taught the course and by this author. Two main categories emerged from the student papers. The first category contained two themes related to pre-trip thoughts and expectations. The second category consisted of two themes that related to what the students had learned and experienced in Kenya.

\section{Theme one: Making a difference}

Students stated that the reason they wanted to go to Kenya was to "make a difference" and get pushed out of their comfort zone. As one student said, "I want to see a part of the world less fortunate than my own life, which has been very easy." Another stated, "I had the opportunity to make a difference and see the world beyond what I have always known it to be."

\section{Theme two: Not knowing what to expect}

The second theme was "not knowing what to expect," which produced a sense of worry and being scared. As one student aptly stated, "No matter how much preparation goes into it, you can never be prepared enough.” Traveling to a country so vastly different from one's own challenges every aspect of a person, including their ability to accept and adapt to a new culture.

\section{Theme three: Feeling like a real nurse}

Theme three related to the realization that the students did know something about nursing care, resulting in a higher level of confidence or "feeling like a real nurse.” One student described having an "aha” moment:

All of a sudden it was like a light went off and I was there by myself, without a clinical instructor looking over my shoulder. I was the one diagnosing, and educating, and I was the one that the children were depending on. It was a very cool moment to kind of realize my nursing potential and essentially what difference we can make.

Another stated "working in the pharmacy was very rewarding, and a place where I learned autonomy as a nursing student to the fullest. ... I grew in my role as a future nurse so much during this experience and it felt really good.” Another student mentioned how creative and flexible she needed to be because she had to "perform care with nothing." Students felt more autonomous working in Kenya and felt they had grown considerably in their roles as future nurses.

\section{Theme four: Renewing my identity}

Students all felt that they had grown as a person and also as an individual living in a global community. Prior to the trip, they did not see themselves as a member of a community larger than where they went to school or where they lived. They described their experiences in Kenya as life changing in several ways. Students related that they had gained perspective and expanded their horizons by having an open mind. They felt they had changed as a person and were different people as a result. One student wrote: 
My journey to Kenya has shaped who I am as a nurse along with who I am as a person. I was able to get a new perspective on life, which I believe will benefit my nursing career... No matter how young or how old; it is just an amazing experience that allows all who go to achieve great personal growth.

The other aspect of growth was seen in the way students viewed the concept of culture shock. Cultural differences were obvious particularly in health care. One student related a patient situation that illustrates these differences:

It is not an ethical dilemma for their culture, but it was culture shock for us. I have a hard time thinking about that mother and not only dealing with her baby's death, but also having to sit with the baby for hours and bury the baby herself.

Kenyan nursing students have increased responsibilities in the care of patients, and this carried over to our nursing students. The impact of cultural differences provided a reality check in the way students viewed what they had in the United States. One student said, "Kenya taught me to focus on what I already have, which is so much.” They realize that they may have taken things for granted due to their increased awareness of global issues. The issue of sustainability also arose in relationship to the health clinics that were held. The importance of working to build long-lasting relationships with the Kenyan people to sustain our health-clinic construction project was evident.

Overall, the students described the trip as "life-changing," resulting in their better understanding of health care and everyday life in a developing country. They appreciated the relative wealth the people in the United States have in terms of money, resources, and health care. They learned that there is a very fine line between life and death in Kenya. They are now aware of the high infant mortality rate during childbirth, which leads to decisions to save a mother rather than to save the child, and about the fact that people die on a daily basis from malaria and dehydration, conditions easily treated in the U.S. They also learned about tropical diseases and how treatments from a local healer may be the first line of care for those with few resources. They saw the kindness and hope that Kenyan people demonstrate every day. They are a hopeful and generous people who give so much despite having so little. These findings are similar to what other schools of nursing have experienced during cultural-immersion trips ${ }^{[3]}$.

\section{I mplications for nursing education}

It has been reported in the literature that educating future nurses about other cultures is proactive and has the potential to decrease health disparities ${ }^{[4]}$. Kollar and Ailinger ${ }^{[5]}$ found that students are more open-minded, have the ability to empathize with others, and are more resistant to stereotyping when they have participated in international trips. Our students expressed the desire to learn more about other cultures and expected that they would return to Kenya or another underdeveloped country to work as RNs. Other positive outcomes of international educational experiences that faculty have observed in our students are an increase in interpersonal and communication skills, as well as the ability to overcome obstacles such as language barriers or cultural differences. These positive outcomes will result in a more culturally competent and open-minded nursing work force.

Preparing nursing and pharmacy students and faculty for international nursing experiences, particularly in underdeveloped countries such as Kenya, requires extensive planning. We have learned from several trips that you can't prepare too much. This preparation needs to be balanced with allowing students to experience a new country from their own perspective. Providing a sound foundation in the basic history, government structure, health care system, and cultural traditions of the country one will be visiting is imperative. It is also important to discuss common health conditions and diseases that participants will encounter to alleviate fear or discomfort that result from lack of knowledge. Preparing students by viewing pictures and hearing stories from former students or from others with experiences from the country ignites excitement about the trip. Ideas for fund-raising and obtaining necessary supplies should be encouraged and ultimately will unite students who may not know each other well. And lastly, having explicit goals and objectives for the trip centers the group and provides structure. 


\section{Conclusion}

As a result of three successful trips to Kenya in the last three years, our School of Nursing has taken the next step in providing international experiences for students. We now offer a 3-week senior capstone experience in Kenya, with capstone experiences in Peru and Ireland in the planning phases. The faculty has seen tremendous growth both personally and professionally in students who have participated in the Kenya trips and feels strongly that international experiences will enhance our nursing and pharmacy curricula to promote cultural competency in our graduates. To assess this growth, a longitudinal, qualitative study is being conducted with students who are participating in the 3-week preceptorship program by interviewing them prior to leaving, upon their return, and one year after the trip. It will be important to ascertain student expectations, their prior knowledge of cultural competence, and the sustainability of what they learn ${ }^{[3,6]}$. Cultural-immersion trips provide students with experiences that force them to examine their personal attitudes and beliefs immediately when they confront differences. Adapting to and reflecting on these differences will ultimately impact their future nursing practice as it relates to cultural competency.

\section{References}

[1] American Association of Colleges of Nursing. Cultural competency in baccalaureate nursing education. Washington, DC: Author.

[2] Peiying N, Goddard T, Gribble N, Pichard C. International placements increase the cultural sensitivity and competency of professional health students: A quantitative and qualitative study. Journal of Physical Therapy Education. 2012; 26 : 61-68.

[3] Maltby H, Abrahms S. Seeing with new eyes: The meaning of an immersion experience in Bangladesh for undergraduate senior nursing students. International Journal of Nursing Education Scholarship. 2009; 6: 1-15. PMid:19883373 http://dx.doi.org/10.2202/1548-923X.1858

[4] Koehn,P. Globalization, migration health, and educational preparation for transcultural encounters. Globalization and Health. 2006; 2: 1-16. PMid:16417625 http://dx.doi.org/10.1186/1744-8603-2-1

[5] Kollar S, Ailinger R. International clinical experiences: Long term impact on students. Nurse Educator. 2002 ; 27 : 28-31. PMid:11840069 http://dx.doi.org/10.1097/00006223-200201000-00016

[6] Larsen R, Reif L. Effectiveness of cultural immersion and culture classes for enhancing nursing students' transcultural self-efficacy. Journal of Nursing Education. 2011; 50: 350-354. PMid:21323246

http://dx.doi.org/10.3928/01484834-20110214-04 